\title{
A liberdade como pré-condição da responsabilidade segundo Hans Jonas
}

\section{Freedom as a pre-condition of responsibility according}

\author{
to Hans Jonas
}

\author{
Marco César de Souza Melo \\ Doutorando em Psicologia - UFC \\ smarcocesar@gmail.com \\ Antonio Glaudenir Brasil Maia \\ Professor de Filosofia - UVA
}

\section{Resumo}

O escopo do presente trabalho é demonstrar como na filosofia do alemão Hans Jonas as categorias liberdade e responsabilidade são relacionadas para solucionar duas das principais questões que permeiam as preocupações do referido filósofo: uma questão epistemológica, traduzida no problema da técnica moderna e, uma questão prática, cujo foco seria a necessidade de uma nova ética para a civilização tecnológica. Segundo Jonas, temos crescido vultuosamente em poder técnico, porém não dispomos de uma ética que oriente 0 uso desse poder, sobretudo no tocante às intervenções técnicas sobre a natureza e seus recursos. Com a articulação dos conceitos de liberdade e responsabilidade o autor acredita superar o dualismo entre ser humano e natureza e instituir uma nova ética cuja centralidade seja a defesa da vida. Para nosso estudo, consultamos algumas das principais obras do autor: $O$ Princípio Responsabilidade: ensaio de uma ética para a civilização tecnológica; O Princípio Vida: fundamentos para uma filosofia da biologia; Técnica, Medicina e Ética: sobre a prática do princípio responsabilidade, Macht oder Ohnmacht der Subjektivitat, e O Conceito de Deus após Auschwitz: uma voz judia. Na primeira parte do trabalho trataremos do conceito de técnica em Jonas e de como o excesso da tecnologia gerou os problemas principais da chamada civilização tecnológica. No segundo momento do texto abordaremos o conceito de liberdade formulado por Jonas em sua filosofia da biologia e como esse conceito implica a superação da dualidade homem e natureza. Por fim, demonstraremos como, segundo o filósofo, a liberdade humana implica no exercício da responsabilidade, de tal modo que, aquela se torna, portanto, pré-condição desta.

Palavras-chave: Liberdade. Responsabilidade. Ética. Hans Jonas.

\section{Abstract}

The scope of this paper is to demonstrate how in the philosophy of German Hans Jonas the categories freedom and responsibility are related to resolve two of the main questions that permeate the concerns of the philosopher: an epistemological question, exposed in 
the problem of modern technique, and a practical question, focusing on the need for a new ethic for technological civilization. According to Jonas, we have grown enormously in technical power, but we do not have an ethic that guides the use of this power, especially in relation to technical interventions on nature and its resources. With the articulation of the concepts of freedom and responsibility the author believes to overcome the dualism between man and nature and establish a new ethics whose centrality is the defense of life. For this study, we consulted some of the author's main works: The imperative of responsibility: in search of an ethics for the technological age.; The Phenomenon of Life: Towards a Philosophical Biology; Technique, Medicine and Ethics: on the practice of the responsibility principle; The Power or impotence of the Subjectivity; and The Concept of God after Auschwitz: A Jewish Voice. In the first part of the paper we will talk about the concept of technique in Jonas and how the excess of technology caused the main problems of technological civilization. In the second moment of the text we will talk about the concept of freedom formulated by Jonas in his philosophy of biology and how this concept implies overcoming the duality of man and nature. Finally, we will demonstrate how, according to the philosopher, human freedom implies the exercise of responsibility, in such a way that the former becomes a precondition of the latter.

Keywords: Freedom. Responsibility. Ethics. Hans Jonas.

\section{Introdução}

No presente texto abordamos os conceitos de liberdade e responsabilidade tal como pensados pelo filósofo alemão Hans Jonas. Nosso objetivo é demonstrar como os dois conceitos são empregados pelo referido filósofo para responder às suas principais preocupações: uma preocupação epistemológica sobre os rumos da racionalidade moderna; e uma preocupação ética sobre a urgência de renovação dos princípios e práticas do agir na, por ele chamada, civilização tecnológica contemporânea.

Hans Jonas experimentou a guerra de pelo menos três perspectivas diferentes: enquanto judeu, viveu os horrores do nazismo e perdeu a mãe vitimada pela câmara de gás no campo de concentração de Auschwitz; enquanto combatente, integrou uma brigada britânica na luta contra Hitler; enquanto intelectual, passou por todas essas experiências sempre com o espírito de instigante observador e não se furtou à tarefa de refletir sobre todos os acontecimentos que marcavam sua época. Nessa terceira condição surgiram as preocupações anunciadas acima e que influenciaram decisivamente todo o seu trabalho filosófico. Se pudéssemos resumir em uma questão o problema jonasiano, diríamos, particularmente, que ele aparece no texto $O$ Conceito de Deus após Auschwitz: uma voz judia, publicado a primeira vez em 1968 como 
atualização da conferência Immortality and The Modern Tempers, proferida em 1961 em Harvard, portanto, sendo o original anterior à publicação de suas obras mais expressivas: O Princípio Vida (1966) e O Princípio Responsabilidade (1979). $\mathrm{Na}$ citada publicação, Jonas levanta a pergunta: "o que fez Auschwitz adicionar ao que sempre se pôde saber sobre a extensão das coisas terríveis e horrendas que os seres humanos podem fazer a outros seres humanos e que desde tempos imemoriais tem feito?" (JONAS, 2016, p. 19).

Com efeito, a pergunta de Jonas se desdobra sobre os caminhos que tomou a racionalidade moderna, que resultou segundo o autor na proeminência da técnica sobre a reflexão e a critica. O pensador também aponta o fato de que todo esse avanço da ciência e da técnica ocorreu desacompanhado de uma ponderação valorativa sobre os fins e os limites do fazer técnico, o que resultou na escravização do homem pela técnica e na crise ambiental.

Nesse texto, reunimos os argumentos com os quais Jonas tenta responder às inquietações epistemológicas e éticas apontadas acima. Veremos que, por um lado, o autor tenta responder ao problema epistêmico criticando o dualismo moderno que separa homem e natureza e institui a ciência e técnica como direcionamento preponderante do conhecimento; por outro lado, no tocante ao problema ético, o autor parte do entendimento da liberdade como algo que deve ser complementado pela responsabilidade gerando uma nova orientação axiológica da ação em relação ao emprego da técnica e ao cuidado com a vida.

\section{A modemidade e a questão da técnica}

Ao se deparar com o fenômeno da barbárie, Jonas percebe a necessidade urgente de repensar os caminhos que a humanidade trilhou e que conduziram à semelhante situação. Dentre as causas da barbárie, Jonas elege como um dos principais motivos o constante declínio da reflexão e o crescente movimento de sobreposição da racionalidade técnica sobre as várias dimensões da vida humana. Inicia, portanto, sua investigação pelo entendimento do que é a técnica e sua aparição na atividade do homem. 
$\mathrm{Na}$ obra Técnica, Medicina e Ética: sobre a prática do princípio responsabilidade, o autor apresenta nos dois primeiros capítulos uma tematização profícua sobre o fenômeno técnico começando por responder a pergunta: Por que a técnica moderna é objeto da filosofia? Aqui, no primeiro capítulo, o autor define a técnica como sendo "o uso de ferramentas e dispositivos artificiais para o negócio da vida" (JONAS, 2013, p. 27). Com efeito, a técnica figura como meio entre as necessidades humanas e os objetos de seu atendimento. $O$ homem como ser biológico, que depende de um processo metabólico de troca de matéria com o meio necessita atender suas demandas para manter sua condição de ente vivo e, para isso, dispõe da produção e utilização de artefatos, ferramentas e mecanismos de aplicação desses recursos mediadores. A técnica é, em última análise, segundo Jonas, uma expressão da vida em movimento, porque expõe a tarefa contínua do homem pela manutenção de sua existência enquanto ser orgânico.

Sendo assim, a técnica nada mais é que uma disposição natural que integra o ser do homem, como uma extensão de si mesmo na sua relação com a exterioridade. Essa disposição é compreendida como capacidade operativa ou saber fazer que o homem desenvolve pela engenhosidade cognitiva e da qual dispõe para manipular as coisas ao seu redor modificando a natureza segundo a sua vontade. Para Jonas, é justamente por ser capacidade humana tão importante e decisiva que a técnica merece aparecer dentre os temas de discussão da filosofia. Além disso, por sua mediação e intervenção sobre a natureza, Jonas a entende como forma própria de ação, isto é, como ação técnica. Esse fator justifica a inscrição da técnica dentre os assuntos concernentes à ética filosófica, correspondendo ao tema do segundo capítulo da citada obra intitulado: Por que a técnica moderna é objeto da ética?

Por conseguinte, Jonas aborda a técnica moderna diferenciando-a da técnica pré-moderna enquanto capacidade de ação e seu alcance objetivo. No horizonte pré-moderno, a técnica possuía como característica distintiva o equilíbrio entre a criação inventiva de ferramentas e o atendimento das necessidades do homem. Tudo quanto se produzia tinha como fim atender uma demanda emergente das próprias condições de existência dos indivíduos em seus diferentes contextos. Sobre isso nos fala Jonas: 
Porque no passado o inventário existente de ferramentas e procedimentos costumava ser bastante constante e tender a um equilíbrio reciprocamente adequado, estático, entre fins reconhecidos e meios apropriados. Uma vez estabelecida tal relação, mantinha-se durante longo tempo como um optimuum de competência técnica sem mais exigências (JONAS, 2013, p. 27).

As produções técnicas permaneciam em uso enquanto durassem as necessidades próprias dos contextos de vida. Além disso, Jonas salienta que "antes de nossos tempos as interferências do homem na natureza, tal como ele próprio as via, eram essencialmente superficiais e impotentes para prejudicar um equilíbrio firmemente assentado" (JONAS, 2006, p. 32). Isso se deve ao fato de que tanto os produtos da técnica eram elementares, quanto o seu emprego não era posto de forma massiva e abrangente. A cada intervenção técnica do homem, a natureza se recompunha em seus recursos podendo atender novamente às necessidades humanas.

Todo esse enquadramento se transforma radicalmente a partir da modernidade, segundo Jonas, sobretudo, devido a nova concepção científica que confere outro entendimento sobre a relação entre o homem e a natureza. Com efeito, Francis Bacon responde por lançar as bases do saber científico da modernidade no que tange aos fins que essa nova ciência deve perseguir: "ele proclamara que conhecimento é poder, e que o objetivo do conhecimento é melhorar a situação terrena do homem, superar as necessidades e misérias humanas" (JONAS, 2017, p. 129). Esse ideal baconiano teria como anteparo a concepção de natureza como matéria informe e disponível para usufruto do homem. A natureza não carrega sentido ou finalidade intrínseca e "a ausência total de causas finais significa que a natureza é indiferente à distinção de valores" (JONAS, 2017, p. 121). Nesse novo contexto, em que a natureza é compreendida apenas como extensão, "o homem fica como o único sujeito e a única vontade" (JONAS, 2017, p. 124) que se impõe na forma de controle das forças mecânicas da natureza física e geometricamente esquematizadas.

A filosofia de Descartes também é evocada por Jonas para essa discussão sobre a separação dualista entre homem e natureza. Consoante nosso autor, Descartes estava convencido de que a matemática é a verdadeira linguagem pela 
qual se expressa o mundo e que todo o movimento se explica através de fenômenos mecânicos. Sobre isso comenta Jonas:

\begin{abstract}
Essa crescente convicção foi erguida por Descartes, à dignidade de um princípio metafísico, quando ele dividiu a realidade em dois domínios mutuamente excludentes, a res cogitans e a res extensa - o mundo do espírito e o mundo da matéria: o último nada é em sua essência senão "extensão"; portanto, para um conhecimento científico do mundo externo não se exige nada mais que as determinações da extensionalidade, isto é, uma geometria (JONAS, 2017, p. 112).
\end{abstract}

A perspectiva pela qual se compreende a natureza, como exterioridade em relação ao homem, é o viés da objetificação materialista. A natureza é reduzida a corpo neutro e enquadrada segundo as leis da matemática, isso deixa margem para a sua exploração completa e submissão aos fins humanos. Segundo Jonas, somente com o aporte nesses pressupostos básicos da ciência moderna é que foi possível o desenvolvimento da técnica moderna, que agora aparece orientada, não à sobrevivência, mas pelos ideais do progresso humano.

No novo cenário da modernidade, ocorre que "cada novo passo em qualquer direção, em qualquer terreno novo da técnica não conduz a um ponto de equilíbrio ou de saturação na adequação dos meios aos objetivos" (JONAS, 2013, p. 29). Isso significa que ficou para trás aquela característica básica da técnica prémoderna do produzir por necessidade. Agora, cada nova descoberta, cada novo artefato técnico criado, cada sucesso na aplicação da técnica conduz ao impulso pela constante superação para o alcance de feitos cada vez maiores.

Não há mais como renunciar ao emprego da técnica quando ela é vista como meio catalizador do progresso. Jonas observa que os progressos científicos nos campos da mecânica, química, biologia e eletrônica favoreceram o surgimento em meados do século XIX do que conhecemos como tecnologia (JONAS, 2017, p. 125). Interessante perceber a distinção entre técnica e tecnologia em Jonas: por um lado o autor utiliza o termo técnica para se referir àquela capacidade humana de mediação instrumental entre as carências e os meios de seu possível atendimento; por outro lado, emprega a palavra tecnologia para descrever o arsenal de produtos resultantes da união entre os avanços da ciência moderna e 
essa mesma capacidade técnica (saber fazer). A técnica moderna, portanto, pode ser definida segundo Jonas como tecnociência, união dos saberes científicos, mormente os experimentais e matemáticos, com fim no aprimoramento da produção de máquinas, ferramentas, instrumentos e métodos de aplicação sofisticados, isto é, produtos tecnológicos. $\mathrm{Em}$ sua obra 0 Princípio Responsabilidade, entretanto, o autor alertará para o perigo que esse novo direcionamento comporta:

Somos tentados a crer que a vocação dos homens se encontra no contínuo progresso desse empreendimento, superando-se sempre a si mesmo, rumo a feitos cada vez maiores. A conquista de um domínio total sobre as coisas e sobre o próprio homem surgiria como a realização do seu destino. Assim, o triunfo do homo faber sobre o seu objeto externo significa, ao mesmo tempo, o seu triunfo na constituição interna do homo sapiens, do qual ele outrora costumava ser uma parte servil. (JONAS, 2006, p. 43).

Dentro dessa compreensão, a tecnociência é colocada como promotora do progresso e benefício da vida humana. Dai por diante produzir e empregar tecnologia para as mais diversas atividades, desde aquelas corriqueiras do cotidiano, passa a ser algo natural. As benesses da tecnologia escondem, porém, as transformações que sutilmente vão ocorrendo, inclusive na própria constituição humana, como bem observa Jonas no trecho citado: aos poucos o homem se torna cada vez mais escravo da técnica, que outrora era tão somente um recurso utilizado conforme a necessidade.

Para Jonas, existe um hiato ético que atravessa o percurso do progresso da ciência e da técnica. Longe de afirmar que a tecnociência seja isenta de valores, o que o autor tenta ressaltar é que faltou, no percurso de crescimento e expansão do fazer científico e tecnológico, uma profunda reflexão sobre os reais fins desse avanço técnico e uma contínua avaliação sobre os potenciais riscos que ele acarretaria. Vivemos em uma civilização que "fundamentou toda a sua forma de vida no trabalho e no esforço de atualização constante de seu potencial técnico" (JONAS, 2013, p. 53), mas que esqueceu da reflexão e da crítica tão necessárias quanto o saber instrumental. $O$ excesso da racionalidade técnica associada ao ideal baconiano de progresso faz com que o homem perca de vista os ideais 
humanísticos, isto é, a cegueira da civilização tecnológica não deixa enxergar o bem humano e dá margem para fenômenos como a barbárie.

Efeitos desse hiato ético se mostram, segundo Jonas, nas próprias condições que caracterizam a chamada civilização tecnológica. A marca dessa civilização é o emprego massivo das tecnologias que, diferentemente de outrora, causam danos irreversíveis à natureza, danos que repercutem na própria dinâmica da vida humana.

Tome-se, por exemplo, como primeira grande alteração ao quadro herdado, a crítica vulnerabilidade da natureza provocada pela intervenção técnica do homem - uma vulnerabilidade que jamais fora pressentida antes de que ela se desse a conhecer pelos danos já produzidos. Essa descoberta, cujo choque levou ao conceito e ao surgimento da ciência do meio ambiente (ecologia), modifica inteiramente a representação que temos de nós mesmos como fator causal no complexo sistema das coisas. (JONAS, 2006, p. 39).

Para o autor, estamos diante de uma dimensão completamente nova do agir técnico. A técnica moderna se nos apresenta, no entender do autor alemão, como ameaçadora para as condições de continuidade plena da vida, seja pela extração e desgaste dos recursos naturais, seja pela exploração da tecnologia nuclear, pelo uso da tecnologia nos processos de massificação da consciência e coisificação do homem. Jonas alerta, portanto, para um índice de empobrecimento da experiência humana nessa civilização tecnológica que é propagandeada tão somente como civilização do progresso. Urge, então, repensar o papel da técnica na sociedade contemporânea e, para isso, como veremos, Hans Jonas encontra respostas na ética filosófica trabalhando, sobretudo, as categorias da liberdade e da responsabilidade.

\section{Liberdade e a solução do problema dualista}

Jonas partiu do curso que o conhecimento científico e a tecnologia tomaram na modernidade e identificou os problemas advindos desse direcionamento. 
Dentre eles aparece de maneira expressiva a sobreposição do fazer técnico ao pensamento reflexivo e contemplativo, que resulta por sua vez no vazio ético no que tange à condução da tecnologia. Para o filósofo, a resolução de tal problemática carece não somente da construção de uma nova ética para a civilização tecnológica, o que ele propõe em sua obra magna $O$ Princípio Responsabilidade, mas exige igualmente uma revisão da relação entre o homem e a natureza, relação esta caracterizada por uma cisão entre ambos.

Na obra O Princípio Vida: fundamentos para uma filosofia da biologia, Jonas propõe uma interpretação filosófica do fenômeno da vida, denominada por ele de filosofia do organismo. Para o autor "o corpo orgânico sinaliza a crise latente de toda ontologia que conhecemos e o critério de toda ontologia futura que se possa aparecer como ciência" (JONAS, 2004, p. 28). Segundo sua biologia filosófica, o funcionamento do organismo carrega elementos que colocam em questão a posição dualista de substâncias entre corpo e mente, uma vez que tal funcionamento é de procedência muito mais integrativa e que dessa integração dependem o aparecimento da unidade de determinação do ser vivo. Em resumo, como bem observou Fonseca (2010), Jonas tenta enfrentar duas formas de dualismo, primeiro o dualismo entre homem e mundo, aquele que estabelece uma relação na forma sujeito/objeto; em segundo lugar o dualismo entre espírito e matéria, ou seja, a separação independente da interioridade e da corporeidade do ser humano. A solução dessa segunda forma de dualismo deve auxiliar a reformulação da relação entre homem e natureza.

De início, Jonas caracteriza o fenômeno da vida orgânica como um movimento dinâmico de tensão entre liberdade e necessidade. Para ele, os organismos vivos são já uma expressão de transcendência perante a inatividade do inorgânico. Essa condição, entretanto, não supera a condição de necessidade, ou seja, os seres vivos precisam atuar na manutenção de sua condição de vivos atendendo suas necessidades básicas.

É possível destacar, segundo o filósofo, pelo menos dois traços fundamentais de distinção entre os seres vivos: "1) a via da percepção; e 2) a via da ação, às quais ele associa respectivamente as dimensões do saber e do poder" (FONSECA, 2010, p. 63). Sendo assim, os seres vivos podem se distinguir de acordo com o grau de percepção e capacidade de movimento que possuem, 
perfazendo uma escala ascendente na qual o ser humano ocupa a posição de maior acúmulo dessas disposições. Para Jonas, quanto maior for o nível dessas capacidades mais livre o ser orgânico será. Nesse sentido, é possível compreender a liberdade como abertura para o mundo que se radica nos graus de possibilidade de percepção e de movimento capazes de externar, no caso do ser humano, a vontade. Assim fala Jonas:

\begin{abstract}
Liberdade, neste sentido descritivo, é um traço ontológico fundamental da vida em si; e também, como se comprova, o princípio contínuo - ou pelo menos o resultado constante - do seu avanço para graus mais elevados, onde a cada passo liberdade se constrói sobre liberdade, liberdade superior sobre liberdade inferior, liberdade mais rica sobre liberdade mais simples (JONAS, 2004, p. 106).
\end{abstract}

Nesse sentido, o conceito de liberdade aparece "como um conceito-guia capaz de orientar-nos na tarefa de interpretar a vida" (JONAS, 2004, p. 106). Isso implica pensar a liberdade "como um processo crescente que surge já nas mais remotas e elementares formas de vida" (FONSECA, 2010, p. 64), que revela através do metabolismo o perseverar do ser orgânico por manter a sua condição. Assim é que segundo Jonas a liberdade se encontra sempre em tensão com a necessidade:

O metabolismo, portanto, a capacidade que distingue 0 organismo, sua soberana primazia no mundo da matéria, é ao mesmo tempo sua forçosa obrigação. Podendo o que pode, ele não pode entretanto, enquanto existir, não fazer o que pode. Possuindo o poder, tem que exercê-lo para existir, e não pode cessar de fazê-lo sem que deixe de existir (JONAS, 2004, p. 107).

Com isso, a liberdade aparece na filosofia de Jonas confundida com a própria aparência dos seres orgânicos em seu modo de funcionar. Liberdade seria a manifestação do organismo na abertura para ser no mundo constantemente buscando a afirmação de si pela manutenção da condição de vivo. Ela seria também a capacidade de manifestação dos seres vivos disposta em graus maiores ou menores da perceptividade e do movimento. Percepção e ação são disposições 
que se manifestam mais elaboradas no organismo humano, refletidas nas capacidades cognitivas e na possibilidade da reflexão sobre a ação. Esse aperfeiçoamento das capacidades será o elemento que distingue o homem na visão de Jonas.

Para Jonas, o homem não é mais um ente desligado das demais formas de vida e do reino orgânico em geral, mas apenas uma forma mais acabada do desenvolvimento vital, no qual a liberdade atinge um grau superior apenas na medida em que tenha emergido já nas suas formas mais primitivas (OLIVEIRA, 2010, p. 79).

O ser humano enquanto ser vivo no qual estão dispostas as melhores capacidades perceptivas e de ação se diferencia dos demais seres orgânicos. Porém, essa distinção não significa uma separação, como bem observa Oliveira (2010) no trecho supracitado. Assim, o homem é entendido por Jonas como "um resultado do progresso que liga o 'primitivo' ao 'evoluído', vindo a representar, pela consciência e pela busca da verdade, o degrau mais elevado desse desenvolvimento" (OLIVEIRA, 2010, p. 79). Por esse olhar, toda a natureza orgânica se encontra integrada numa totalidade, somente se distinguindo em termos de níveis de aparecimento das disposições perceptivas e de ação, que no homem resultam no aparecimento da consciência, da reflexão e do agir planejado.

Ao prosseguir sua investigação filosófica sobre os fenômenos biológicos, Jonas tenta resolver o dualismo corpo/espírito pela explicação da relação entre percepção e movimento. O tema da causalidade psicofísica é tratado de modo mais demorado no ensaio intitulado Poder o Impotencia de la Subjetividad (2005) que, segundo o autor deveria ser um capítulo complementar ao terceiro e ao quarto capítulos de $O$ Princípio Responsabilidade, capítulos nos quais Jonas fala da possibilidade de um movimento teleológico na natureza.

A proposta de Jonas é a interpretação do organismo na forma de um monismo integral, que não separa interioridade de exterioridade, isto é, defende que nos seres orgânicos interioridade e exterioridade são faces complementares de um mesmo ser. Nos organismos não humanos, a dimensão perceptiva se manifesta na orientação do movimento, pela nutrição, a procura de autodefesa, segurança e interação de modo geral com o meio. No ser humano, as capacidades 
perceptivas se desdobram nas emoções e no pensamento. Isso implica na afirmação de que a interioridade está presente em toda forma de vida, distribuída em diferentes níveis ou graus. No caso do ser humano, Jonas se preocupa em explicar como ocorre a causalidade psicofísica, ou seja, como o pensamento se relaciona com a ação.

Na obra Hans Jonas e a Filosofia da Mente Viana (2016) retoma os estudos jonasianos que conduziram à produção do ensaio Macht oder Ohnmacht der Subjektivitat e depois de uma longa exposição detalhada do percurso argumentativo do filósofo, expõe por fim sua posição: segundo Jonas, a relação entre pensamento e ação no homem ocorre mediante transferências de energia em graus mínimos, que não chegam a afetar as leis da natureza. Assim, vejamos:

Jonas sugere que, na esfera em que o espírito escolhe livremente uma ação (nos estados puramente mentais), aconteceria a influência de uma força capaz de gerar no nível quântico um crescimento energético de magnitude tão pequena e imperceptível no macrocosmo que influenciaria os pontos desencadeantes e geraria todo o movimento posterior até a ação corporal. Segundo Jonas, a força inicial (quase nula) exercida nos pontos desencadeantes não afetaria nem quebraria as leis determinísticas do macrocosmo, o que contornaria a crítica segundo a qual uma interação psicofísica seria contra as leis da conservação da energia ou da visão determinista do macrocosmo. Jonas crê que seu modelo conserva tanto a integridade das leis da natureza quanto a certeza intuitiva da eficácia do espírito (VIANA, 2016, p. 205).

Nesse sentido, vemos o esforço da argumentação de Jonas no sentido de promover um entendimento da causação psicofísica, conferindo um poder de determinação na integração corpo/mente. Aliás, para Jonas tudo acontece no substrato orgânico, pois, segundo o trecho exposto, o autor nos leva a crer que o pensamento e a vontade são disposições que ocorrem na própria dinâmica funcional do organismo de maneira que "todo discurso sobre o espírito também deve se referir ao corpo e à matéria; referir-se à subjetividade é referir-se a seus objetos externos, ou seja, ao mundo físico." (JONAS, 2005, p.145, tradução nossa). Importante ressaltar o comentário sobre o limite das leis do macrocosmo, não ultrapassado pelo processo psicofísico. Interessante notar que Jonas explica 
como acontece a determinação da ação pelo pensamento, colocando isso em termos de uma abertura para transferências de energia que seguem movimentos próprios distintos das leis do macrocosmo sem nelas interferir. É assim que o autor tenta assegurar seu conceito de liberdade, situando-o dentro dos processos concernentes ao ser orgânico, isto é, o organismo, por sua própria natureza, é que marca o aparecimento da liberdade.

Com isso, Jonas pretende superar tanto o dualismo entre espírito e corpo quanto o dualismo homem e natureza. A filosofia do organismo indica que os seres vivos são uma unidade psicofísica cujas faces, interior e exterior, são indivisíveis e inseparáveis, compõem elas um mesmo e único ser vivente. Sendo o homem um ser orgânico, que partilha das mesmas disposições básicas dos demais seres vivos, ele não pode ser separado do restante da natureza, mas compor com ela uma unidade complementar. Esse último ponto é caro a Jonas para a sua formulação da ética da responsabilidade, justamente porque as capacidades das quais o homem dispõe lhe capacitam para o exercício voluntário da responsabilidade. $\mathrm{O}$ homem, como ser que se distingue por capacidade maior de pensamento e de ação, é o único dentre os seres capaz, portanto, de responsabilidade.

\section{A responsabilidade no horizonte da liberdade humana}

Todo o caminho trilhado por Jonas, no âmbito de sua reflexão ética, tem como ponto de partida as inquietações sobre os rumos da ciência e da técnica moderna que, de acordo com seu diagnóstico, resultam nas condições problemáticas que açambarcam a civilização tecnológica contemporânea. A técnica moderna se tornou uma ameaça à vida, não só pelo arsenal tecnológico de destruição do qual dispomos, mas também pelo esquecimento de que o homem é um ser participante da natureza. O excesso de razão técnica e o poder exercido sobre a natureza fizeram com que o homem esquecesse seu lugar no mundo e é em torno desse ponto que vão girar boa parte dos esforços de Jonas na elaboração da ética da responsabilidade. 
De início, Jonas situa a responsabilidade como corolário da liberdade do homem. Responsabilizar-se por algo é uma consequência da capacidade de ação livre que o homem detém, mas ele pode escolher entre assumir ou não a responsabilidade. Sobre esse aspecto, nos diz Jonas:

A capacidade de responsabilidade, que é uma capacidade ética, se baseia na capacidade ontológica do ser humano de escolher entre seus conhecimentos e vontade entre alternativas de ação. A responsabilidade é, portanto, complementar à liberdade (JONAS, 1992, p. 138, tradução nossa).

Jonas propõe pelo menos duas maneiras de entender a responsabilidade: a primeira, já sinalizada acima, diz respeito à opção por tornar-se responsável por algo, um objeto da escolha livre pelo cuidado de algo; a segunda é apresentada por Jonas como uma resposta relativa a ações tomadas, isto é, somos responsáveis por nossos atos. Nossas atitudes tocam um outro, por isso, podemos responder pelo que fazemos e como afetamos as coisas ao nosso redor. No tocante à natureza, o homem da civilização tecnológica é responsável pelas ações destrutivas que o uso da tecnologia vem promovendo. Esse potencial destrutivo compromete a vida orgânica de modo geral, inclusive a do próprio homem, de diversas formas. Por isso é que, para Jonas, o objeto principal da responsabilidade deve ser a vida.

Essa responsabilidade pode ser reivindicada como resposta aos atos nocivos que a intervenção técnica causa à vida em geral, como também pode ser um exercício voluntário do cuidado pela natureza e a defesa da vida. É nisso que consiste a centralidade da ética da responsabilidade, que o autor expressa no seguinte imperativo: "age de modo a que os efeitos de tua ação sejam compatíveis com a permanência de uma autêntica vida humana sobre a terra" (JONAS, 2006, p. 47). O exercício da responsabilidade se converte em um cuidado pela vida ameaçada no contexto da técnica moderna. Jonas argumenta que dispor de maior capacidade perceptiva e de agência acarreta por um lado um ganho, que é a posse de um nível superior de liberdade, mas, por outro lado acarreta também a responsabilidade que se traduz no cuidado e defesa da vida. O exercício voluntário da responsabilidade compreende uma função ética que tem por base o 
valor da vida enquanto condição inviolável e, por isso, é dever do sujeito de responsabilidade trabalhar pelo resguardo da vida e combater a barbárie.

\section{Considerações finais}

Percebemos que Hans Jonas direciona seu esforço filosófico para a interpretação de toda a situação da civilização que ele chamou de tecnológica, justamente pela abrangência dos processos técnicos sobre a dinâmica das sociedades modernas. Seu exame expressa que, de um ponto de vista epistêmico, desde a modernidade a produção do saber científico potencializou a técnica em detrimento da reflexão e, no tocante à moralidade, apontou a necessidade de uma ética que conduzisse os processos de desenvolvimento da técnica, resultando nos problemas advindos do tecnicismo, tais como a escravização do homem pela técnica e a degradação da natureza.

A solução que o autor apresenta passa pela reconsideração do lugar do homem em relação à natureza. Para o filósofo, o homem não pode mais se enxergar como senhor da natureza, mas sim como participante dela. $O$ fundamento dessa assertiva Jonas vai buscar nos estudos de biologia filosófica, tentando compreender os processos do mundo orgânico para superar o dualismo de substâncias. Ele acaba por extrair desses estudos também seu original conceito de liberdade. A liberdade humana, segundo ele, deve implicar a responsabilidade, princípio fundamental de uma nova eticidade. Em resumo, seria esse o roteiro que tentamos perfazer nas linhas deste artigo, reunindo os argumentos expressos nas principais obras do autor em estudo.

Consideramos importante a intenção de Jonas em tentar interpretar os problemas da civilização tecnológica atual e percebemos que seu diagnóstico sobre a preponderância da tecnologia sobre as mais diversas situações da vida é pertinente e atual. Acreditamos, contudo, que, no tocante à biologia filosófica alguns argumentos do autor necessitariam de melhor aprofundamento, sobretudo, no tocante à identificação de fins intrínsecos à natureza e à solução apresentada ao problema do dualismo. Embora o autor defenda a integração orgânica do sujeito, a comunicação entre pensamento e movimento físico nos parece ainda 
colocada como relação entre instâncias distintas. Contudo, é reconhecível o mérito das reflexões desse autor, que instigam nosso interesse por entender a sociedade tecnológica atual e procurar soluções razoáveis para os problemas que a técnica nos apresenta.

\section{Referências}

FONSECA, L. S. G. Liberdade na necessidade ou a resolução do dualismo segundo Jonas. In: Dissertatio Revista de Filosofia, UFPel [32, 2010], p. 55-75.

JONAS, H. Pensar sobre Dios y otros ensayos. Barcelona: Herder, 1992.

O princípio vida. Fundamentos para uma biologia filosófica. Tradução: Carlos Almeida Pereira. Petrópolis, RJ: Vozes, 2004.

. Poder o Impotencia de la Subjetividad. Barcelona/Espanha: Paidós, 2005.

- O princípio responsabilidade: ensaio de uma ética para a civilização tecnológica. Rio de Janeiro: Contraponto, 2006.

Técnica, Medicina e Ética: sobre a prática do princípio responsabilidade. São Paulo: Paulus, 2013 (Coleção Ethos).

2016.

O Conceito de Deus após Auschwitz: uma voz judia. São Paulo: Paulus, Paulus, 2017.

Ensaios Filosóficos: da crença antiga ao homem tecnológico. São Paulo:

OLIVEIRA. J. R. A transanimalidade do homem: uma premissa do Princípio Responsabilidade. In: Dissertatio Revista de Filosofia, UFPel [32, 2010], p. 77- 97.

VIANA, W. C. Hans Jonas e a Filosofia da Mente. São Paulo: Paulus, 2016. 